\title{
Examining Handwashing Care in Assisted-Living Facilities from the Perspective of Hand and Finger Stimulation to Induce Brain Activation in the Residents
}

\author{
Atsuko Tokushige \\ Faculty of Nursing, Setsunan University, Hirakata, Japan \\ Email: tokushige@nrs.setsunan.ac.jp \\ Received 21 January 2016; accepted 22 February 2016; published 25 February 2016 \\ Copyright (C 2016 by authors and Scientific Research Publishing Inc. \\ This work is licensed under the Creative Commons Attribution International License (CC BY). \\ http://creativecommons.org/licenses/by/4.0/

\section{c) (i) Open Access}

\begin{abstract}
The elderly who is confined to bed or demented may choke if their cerebrum is not sufficiently aroused while eating. Therefore, this study focused on determining if hygienic care of the hands and fingers would have a biologically stimulative effect and on verifying whether using a warm cloth or warm water was more effective for cerebral activation. The results suggest that when assisting the elderly in washing their hands, from the perspective of cerebral activation, using warm water is better than using a warm cloth.
\end{abstract}

\section{Keywords}

Electroencephalogram, Cerebral Activation, Sitting Position, Handwashing Care, Elderly

\section{Introduction}

Bedridden elderlies and elderlies with dementia may choke if their cerebrum is not sufficiently aroused when they are to eat. From this vantage point, providing nursing care that will raise the level of alertness before a meal may be necessary.

According to the 2013 Vital Statistics compiled by Japan's Ministry of Health, Labour and Welfare, accidental death was the sixth leading cause of death for people over 65 years of age. When cases of accidental death are categorized by the specifics, in the order of highest to lowest for those between ages 65 and 79, it can be seen that $25.3 \%$ of the cases involve accidental drowning and near drowning, 20.7\% involve other accidental choking, and $17 \%$ involve tripping/falling. For those older than 80 years of age, $31.4 \%$ of accidental deaths are 
due to other accidental choking, $24.1 \%$ due to tripping/falling, and $17 \%$ due to accidental drowning and near drowning, making choking the biggest cause of death among accidental deaths. The breakdown of choking-related deaths shows "swallowing food the wrong way causing respiratory tract obstruction" being the biggest cause at $11.6 \%$ for the 65 to 79 age group and $14.5 \%$ for the 80 or older age group [1].

According to the ICD-10 (International Statistical Classification of Diseases and Related Health Problems, 10th revision) by the WHO, inhalation and ingestion of food causing obstruction of the respiratory tract is listed as a cause of death under section W79 [2]. In addition, there are also reports that the elderly over the age of 65 in the United States of America experience higher incidents of choking on food [3].

Based on the above, choking on food is an accident commonly seen in the elderly population, and it is important to keep the choking factor in mind when providing nursing care. Therefore, providing nursing assistance that will help awaken the cerebrum is vital.

Up until now, I have studied the cerebral activity produced by the postural change from supine to sitting position in healthy adults, healthy elderly, and the elderly residents in facilities as my subjects. The results of these studies show that in the case of the elderly in assisted living facility, the cerebral activation does not take place when they are raised to a sitting position on the bed; therefore, assisting them to sit on a chair or a wheelchair is necessary [4] [5]. Based on these studies, I postulated that if we were to reduce incidents of choking on food, it would be necessary to awaken the brain. Therefore, as much as possible, when helping the elderly eat, we should assist them out of the bed and into in a sitting position on a seat as long as they are capable of doing so. Our hands are important sensory organs, as it is aptly said, "the hand is the visible part of the brain". Therefore, I surmise that combining the sitting posture with hand stimulation may raise the alertness or wakefulness of the brain. Thus, caregiving through assisting handwashing before meals is conceived as the idea behind this research.

Thus far, whenever I have randomly checked nursing textbooks available on the market, I find that at least in Japanese nursing education, handwashing before meals is categorized under "assisting hygiene" by keeping the hands and fingers clean [6]-[9]. As to the effect of hand bathing, in addition to maintaining hygiene, relaxation [10] [11] and increase in peripheral skin temperature [12] [13] were reported. The clinical effects of hand bathing include sensory stimulation in children with acute encephalopathy [14] and aiding sleep in the elderly [15] [16]. There are also some reports on efforts to improve the level of consciousness through hand bathing in patients with cerebrovascular disease in academic gatherings, but so far, there are hardly any published papers on handwashing and alertness in Japan. Additionally, in Japanese hospitals and facilities for the elderly, many places provide warm cloths as a way to keep the hands and fingers clean before meals, but they do not assist in washing hands.

As described thus far, neither education nor caregiving focuses on the relation between handwashing and the level of alertness. If this study could show that handwashing is more effective in increasing one's alertness than using warm cloths, this could be meaningfully presented as a method of providing nursing care that will help raise the level of alertness before starting a meal.

However, it is not easy to simply compare handwashing against the use of a warm towel as cleaning agents may be used, or it may involve complex movements such as hand rubbing, and the water pressure and differences in water temperature may have an influence as well. Therefore, this study was designed to perform basic verification of comparing the differences in cerebral activity during the use of a warm towel or warm water in a basin.

\section{Methods}

\subsection{Data Collection}

Two sets of studies were set up, one with healthy adults (Experiment 1 ) and one with the elderly residents in an assisted living facility (Experiment 2). I conducted Experiment 1 in 2010, and Experiment 2 in 2011, and both researches were conducted before lunchtime.

In this basic research study, a set up was designed to provide heat stimulation to hands and fingers by using warm cloths or warm water for the purpose of hygienic care, after which tactile sensory stimulation was provided through drying off with a dry towel. Each activity was evaluated for cerebral response by the measurement of brain waves.

In addition, in preparation for this study, brainwaves of healthy adults were analyzed for their response to 
stimulation of the hand and fingers by warm cloths, and comparisons were made between the supine state and sitting position. Significant activation of the cerebrum was observed when in the sitting position. The subjects were 9 individuals, and as it presented significant differences, I set the number of the subjects as 10 or more individuals.

\subsubsection{Experiment 1}

\section{1) Subjects}

Healthy adults in their $20 \mathrm{~s}$ to $30 \mathrm{~s}$ were selected as subjects. Since it is known that there are differences between the sexes in autonomic nervous activities, in Experiment 1, only females were selected.

2) Measured Items

a) Electroencephalographic (EEG) Data

Two measuring points ( $\mathrm{Fp}_{1}$ : left frontal lobe and $\mathrm{C}_{3}$ : left centroparietal regions) based on the International 10 20 System were selected.

\section{b) Subjective Survey}

I evaluated the subjects for the level of alertness when receiving tactile sensory stimulation.

3) Study Procedure (Figure 1)

All participants were subjected to both warm cloth and warm water. In both cases, stimulation was only given on the right hand. The posture was set in a sitting position, with the back against the back of a chair and bottom of the feet touching the floor.

In the study using a warm cloth, first both hands from the tip of the finger to the wrist were covered with a warm cloth at a temperature range of $39^{\circ} \mathrm{C}$ to $42^{\circ} \mathrm{C}$ (heat stimulation: 1 minute), and then a dry towel was used for wiping (tactile sensory stimulation: 1 minute).

In the study using warm water, the right hand up to the wrist was soaked in a basin of warm water at a temperature range of $39^{\circ} \mathrm{C}$ to $42^{\circ} \mathrm{C} \mathrm{(1} \mathrm{minute)} \mathrm{and} \mathrm{afterwards} \mathrm{wiped} \mathrm{with} \mathrm{a} \mathrm{dry} \mathrm{towel} \mathrm{(1} \mathrm{minute).} \mathrm{Pat} \mathrm{drying} \mathrm{was} \mathrm{the}$ method used for wiping rather than rigorous wiping. This measurement time was set to be similar to the normal daily behavior, and to provide time necessary to analyze the brain waves.

After each experiment, the subjects were given a subjective survey. They were asked (using a self-administered questionnaire), between the use of a warm cloth or the use of warm water, which did they feel raised their level of alertness more?

4) Analysis Method

a) Setting the Data Points

Data points for analysis were set as "resting (baseline 3 minutes)", "heat stimulation (1 minute)", "tactile sensory stimulation (1 minute)", and "resting (5 minutes)".

b) Analysis of the Signal Processing of the Brainwaves and Its Power Values

$\alpha$-band $(8 \sim 13 \mathrm{~Hz})$ and $\beta$-band $(13 \sim 30 \mathrm{~Hz})$ were analyzed, and the brainwave power values in those band-

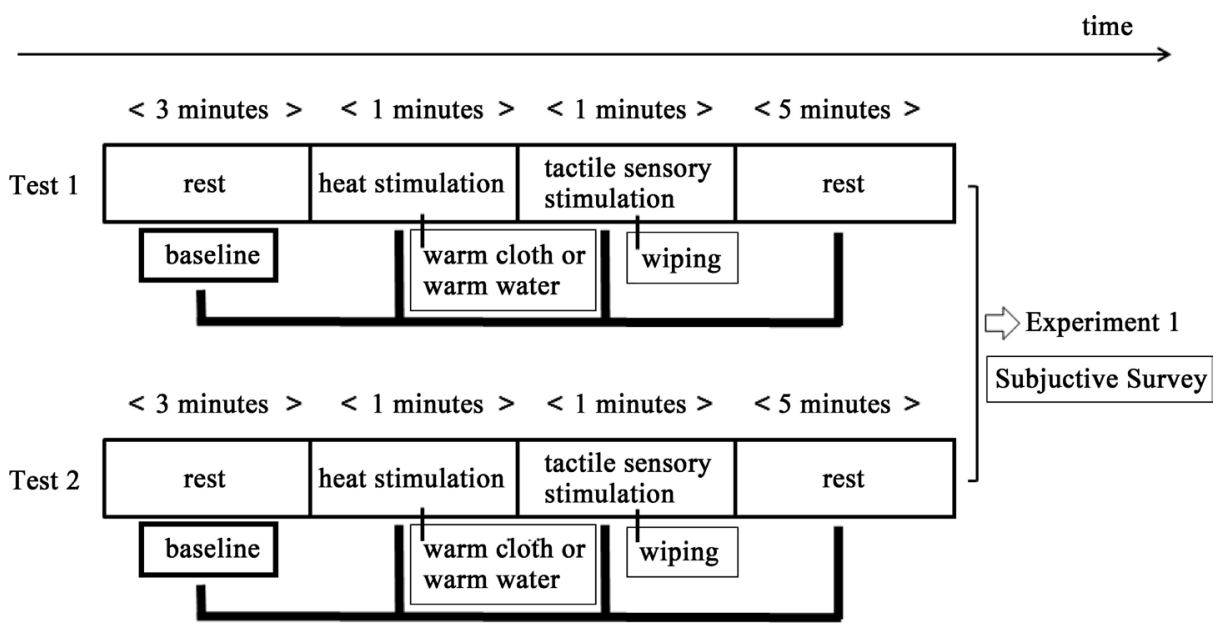

Note: All participants were subjected to both warm cloth and warm water.

Figure 1. Study procedure. 
widths (Unit: $\mu \mathrm{V} 2$ ) were calculated for each data segment. The power values used for comparison were selected from the stable periods of each time segment and the average of 6 segments at 10 seconds each (totaling 1 minute at each segment) were used as the power value.

c) Statistical Analysis

Multiple comparisons were made between the power values of the brainwaves at baseline and when using a warm cloth or warm water as well as during tactile sensory stimulation. Additionally, results from the two groups using warm cloths or warm water were compared.

Since the resulting EEG data did not have a normal distribution, a nonparametric technique for statistical analysis was used.

In comparing the resting state with each stimulus, I conducted multiple comparisons using Wilcoxon signed-rank test along with Bonferroni corrections to adjust the level of significance (Level of Significance $=0.016 \fallingdotseq$ 0.05/3). In comparing the use of warm cloth and warm water, Wilcoxon signed-rank test was used, and the values were based on the differences from the respective baselines.

For the subjective survey, the answers were simply compiled and evaluated to obtain the ratio.

\subsubsection{Experiment 2}

\section{1) Subjects}

The subjects were selected from the elderly residents of an assisted-living facility. The dementia level (determination of the ability for the elderly diagnosed with dementia to live an independent life) was set from "no sign of dementia" to level "II". The "the independence degree of the elderly diagnosed with dementia" is a standard set by the Ministry of Health, Labour and Welfare. "II" means that one is in a state where "independent living is still possible as long as someone is there to watch over the individual though there are signs of symptoms, behavior, actions, and difficulties in mutual understanding seen at home that affect one's daily life.”

2) Measurement Items

EEG data were obtained from the subjects in Experiment 2.

Four measuring points $\left(\mathrm{Fp}_{1}\right.$ : left frontal lobe, $\mathrm{Fp}_{2}$ : right frontal lobe, $\mathrm{C}_{3}$ : left centroparietal, and $\mathrm{C}_{4}$ : right centroparietal regions) based on the International 10 - 20 System were selected.

3) Study Procedure

The same procedure as that used in Experiment 1 was followed.

The subjective survey was not conducted in Experiment 2, but all other procedures were the same as in experiment 1 (Figure 1).

4) Analysis Method

The same method as used in Experiment 1 was followed.

\subsection{Ethical Consideration}

This study was reviewed and approved by the ethics committee of Meiji University of Integrative Medicine as the researcher's previous workplace. All personal information obtained through the research is kept private, and significant precautions were taken to protect the privacy of the individuals in conducting this study.

The subjects of Experiment 1 were the students of the university the researcher belongs to, and the subjects of Experiment 2 were the residents of an assisted-living facility in the area where the university is located.

For both Experiment 1 and 2, the subjects were invited to participate through a public appeal, and those who applied to join the study were explained the following orally and in writing: the purpose of the study; the method of the study; the nature of cooperation in the participation of the study as well as the freedom to decline; the protection of private information; and the reporting of the results. After this, an agreement was signed. Experiment 2 was conducted by providing the explanation with the help of the facility staff, and the consent to the study was obtained from the subjects themselves and their legal caregivers, such as their family members, as well.

\section{Results}

\subsection{Results of Experiment 1 (Table 1 and Table 2)}

\subsubsection{Subjects (Table 1)}

Sixteen healthy adult females consented to their participation in the study. The average age and the standard 
Table 1. Basic demographic data of healthy adults.

\begin{tabular}{cccc}
\hline Subject & Age & Sex & Dominant Hand \\
\hline A & 21 & female & right \\
B & 21 & female & right \\
C & 20 & female & right \\
D & 21 & female & right \\
E & 26 & female & right \\
F & 24 & female & right \\
G & 23 & female & right \\
H & 21 & female & right \\
I & 21 & female & right \\
J & 21 & female & right \\
K & 21 & female & right \\
L & 21 & female & right \\
M & 21 & female & right \\
N & 20 & female & right \\
O & 21 & female & right \\
P & 21 & female & right \\
average & 21.1 & & \\
standard deviation & 0.74 & &
\end{tabular}

Table 2. $\alpha$-Band brainwave power values of healthy adults.

\begin{tabular}{|c|c|c|c|c|}
\hline & \multicolumn{2}{|c|}{ Warm Cloth } & \multicolumn{2}{|c|}{ Warm Water } \\
\hline & Power Value & Wilcoxon Test & Power Value & Wilcoxon Test \\
\hline \multicolumn{5}{|l|}{$\mathbf{F} \mathbf{p}_{1}$} \\
\hline Resting (baseline) & $19.2 \pm 3.7$ & - & $17.4 \pm 3.3$ & - \\
\hline Heat Stimulation & $16.0 \pm 2.8$ & 0.438 & $18.0 \pm 2.2$ & 0.134 \\
\hline Tactile Sensory Stimulation & $15.0 \pm 2.3$ & 0.301 & $13.8 \pm 2.2$ & 0.959 \\
\hline Resting & $17.1 \pm 3.0$ & 0.278 & $17.2 \pm 2.6$ & 0.717 \\
\hline \multicolumn{5}{|l|}{$\mathrm{C}_{3}$} \\
\hline Resting (baseline) & $24.1 \pm 5.3$ & - & $18.4 \pm 4.0$ & - \\
\hline Heat Stimulation & $14.1 \pm 2.7^{*}$ & 0.006 & $15.4 \pm 1.9^{*}$ & 0.605 \\
\hline Tactile Sensory Stimulation & $13.4 \pm 2.3$ & 0.015 & $11.4 \pm 2.3$ & 0.109 \\
\hline Resting & $18.9 \pm 3.4$ & 0.163 & $20.5 \pm 4.9$ & 0.255 \\
\hline
\end{tabular}

Note: $\mathrm{n}=16$. $\mathrm{Fp}_{1}$ : left frontal lobe region, $\mathrm{C}_{3}$ : left centroparietal region.

Power Value is an average value $\pm \mathrm{SE}\left(\mu \mathrm{V}^{2}\right)$.

$\mathrm{p}$-value is used to show the results of multiple comparisons.

$\mathrm{p}<0.016$ is set as the level of significance (with Bonferroni correction).

*: Significant difference data, Comparison between Warm Cloth and Warm Water, Mann-Whitney U test.

deviation were $21.10 \pm 0.74$ years. There were no missing data, so the entire data was used for analysis.

\subsubsection{Electroencephalographic Data (Table 2 and Table 3, Figure 2)}

At $\mathrm{Fp}_{1}$, there was a significant increase in the $\beta$-band power value $(\mathrm{p}<0.05)$ with heat stimulation produced by a warm cloth compared to the resting state. In comparing the resting state at $C_{3}$, during heat stimulation and tactile sensory stimulation, $\alpha$-band power value decreased significantly $(\mathrm{p}<0.05)$.

When comparing the use of warm water to the resting state, with its heat stimulation, a significant increase in the $\beta$-band power value $(\mathrm{p}<0.05)$ at $\mathrm{Fp}_{1}$ was seen. 
Table 3. $\beta$-Band brainwave power values of healthy adults.

\begin{tabular}{ccccc}
\hline & \multicolumn{2}{c}{ Warm Cloth } & \multicolumn{2}{c}{ Warm Water } \\
\cline { 2 - 5 } & Power Value & Wilcoxon Test & Power Value & Wilcoxon Test \\
\hline Fp $_{\mathbf{1}}$ & & & & \\
\hline Resting (baseline) & $10.2 \pm 1.6$ & - & $10.2 \pm 1.8$ & - \\
Heat Stimulation & $14.4 \pm 2.3$ & 0.001 & $12.5 \pm 1.8$ & 0.000 \\
Tactile Sensory Stimulation & $12.8 \pm 2.5$ & 0.134 & $10.2 \pm 1.4$ & 0.756 \\
Resting & $12.3 \pm 2.3$ & 0.234 & $15.8 \pm 3.5$ & 0.098 \\
\hline C 3 & & & & $0.4 \pm 0.8$ \\
\hline Resting (baseline) & $8.9 \pm 1.0$ & - & $10.5 \pm 0.9$ & 0.004 \\
Heat Stimulation & $9.8 \pm 0.9$ & 0.196 & $8.0 \pm 0.8$ & 0.552 \\
\hline Tactile Sensory Stimulation & $10.3 \pm 2.0$ & 0.959 & $8.9 \pm 1.0$ & 0.234 \\
\hline
\end{tabular}

Note: $\mathrm{n}=16$. Fp $\mathrm{p}_{1}$ : left frontal lobe region, $\mathrm{C}_{3}$ : left centroparietal region.

Power Value is an average value $\pm \mathrm{SE}\left(\mu \mathrm{V}^{2}\right)$.

p-value is used to show the results of multiple comparisons.

$\mathrm{p}<0.016$ is set as the level of significance (with Bonferroni correction).

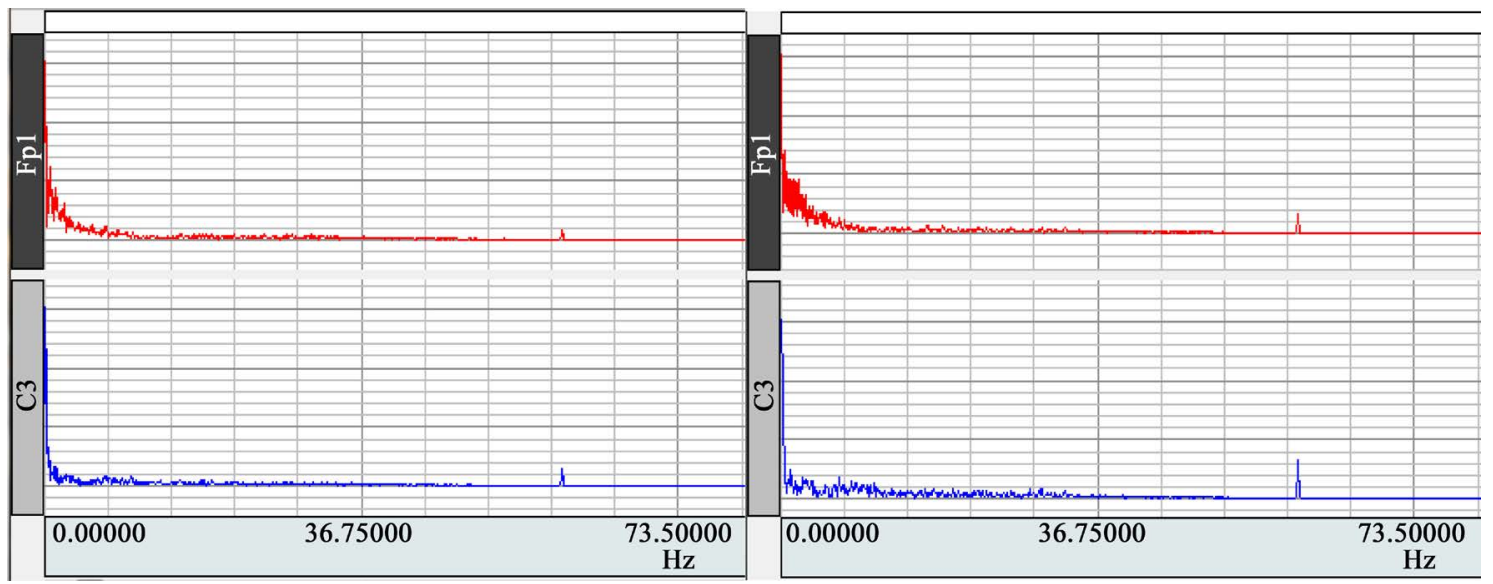

Note: Data at the time of heat stimulation.

(a)

(b)

Figure 2. Electroencephalographic data of healthy adults. (a) Heat stimulation (warm cloth); (b) Heat stimulation (warm water).

In comparison to the resting state, using warm water for heat stimulation showed a significant increase in the $\beta$-band power value $(\mathrm{p}<0.05)$ for both for $\mathrm{Fp}_{1}$ and $\mathrm{C}_{3}$. When the stimuli of the warm cloth and warm water were compared at $\mathrm{C}_{3}$, the $\alpha$-band power value showed a decrease during heat stimulation with a warm cloth, significantly more so than with the use of warm water.

In comparing the use of a warm cloth and warm water, the heat stimulation from the warm cloth caused a more significant decrease in $\alpha$-band power value at $\mathrm{C}_{3}$ compared to the use of warm water $(\mathrm{p}<0.05) . \beta$-band power value did not show any significant difference.

\subsubsection{Subjective Survey}

Between the warm cloth and warm water, 13 out of 16 people said they felt more awake with warm water $(\mathrm{p}=$ 0.021).

\subsection{Results of Experiment 2}

\subsubsection{Subjects (Table 4)}

Ten individuals (eight females and two males) who were residents in an assisted living facility agreed to partic- 
Table 4. Basic demographic data of the elderly in an assisted living facility.

\begin{tabular}{cccc}
\hline Subject & Age & Sex & Dementia Level $^{*}$ \\
A & 81 & female & independence \\
B & 63 & male & independence \\
C & 85 & male & independence \\
D & 86 & female & IIa \\
E & 85 & female & IIb \\
F & 98 & female & I \\
G & 89 & female & I \\
H & 84 & female & IIb \\
I & 91 & female & IIa \\
J & 94 & female & \\
average & 85.60 & & \\
\hline
\end{tabular}

Note: ${ }^{*}$ Independence degree of daily living for the demented elderly (Ministry of Health, Labour and Welfare, Japan).

Level I: He/She has certain condition(s) of dementia, but can lead mostly independent day-to-day life at homand in the society.

Level II: Though he/she may have some condition(s) that interfere with his/her daily life, or have difficulties to communicate with others, he/she can be independent with someone watching.

Level IIa: T He/she is observed with the condition(s) of the above-mentioned II outside home.

Level IIb: He/she is observed with the condition(s) of the above-mentioned II at home as well.

Level III: He/she is observed with condition(s) and behaviors that interfere with his/her day-to-day life, and he/she is in need of care.

Level IIIa: He/she is observed with the condition(s) of above-mentioned III mostly in daytime.

Level IIIb: He/she is observed with the condition(s) of above-mentioned III, mostly during night time.

Level IV: He/she is frequently observed with condition(s), behaviors and difficulties to communicate with others, and he/she is in need of care throughout the day.

Level M: He/she is observed with severe mental condition(s) and peripheral condition(s), or serious physical disorder(s), and he/she is in need of medical attention.

ipate in this study. The average age and the standard deviation were $85.6 \pm 9.4$ years. There were no missing data, so the entire data was used for analysis.

\subsubsection{Electroencephalographic Data (Table 5 and Table 6, Figure 3)}

In comparing the use of a warm cloth to the resting state, the $\beta$-band power value significantly increased with heat stimulation at $\mathrm{C}_{3}(\mathrm{p}<0.05)$. At $\mathrm{C}_{4}$, in comparing the resting state to that during heat stimulation and tactile sensory stimulation, the $\beta$-band power value had significantly increased $(\mathrm{p}<0.05)$.

In the use of warm water, the $\alpha$-band power value showed a significant increase with heat stimulation at $\mathrm{C}_{3}$ as well as at $\mathrm{C}_{4}$ and in comparison to the resting state, tactile sensory stimulation also caused a significant increase $(\mathrm{p}<0.05)$. In all measurement points, in both heat stimulation and tactile sensory stimulation, $\beta$-band power value showed a significant increase compared to the resting state $(\mathrm{p}<0.05)$.

In the comparison of the warm cloth and warm water, there were no significant differences in $\alpha$-band or $\beta$-band power values.

\section{Discussion}

When comparing the $\beta$-band power value that shows the activated state of the brain to that of the resting state of the brain, an increase in the $\beta$-band power value was seen in both the use of warm cloth and warm water in both research 1 and 2. However, the use of warm water was more consistently seen as having a statistically significant difference. It was clear that in the case of the elderly residing in the assisted living facility, in all its measuring points, in both heat stimulation and tactile sensory stimulation, the power value of the $\beta$-band brainwave increased significantly compared to the resting state, demonstrating that these actions were stimulating the cerebrum.

The above results suggest that when assisting the elderly to wash their hands, the use of warm water is better than using warm cloths from the perspective of cerebral activation.

In healthy adults, no significant increase in brainwave power value can be observed with tactile sensory 
Table 5. $\alpha$-Band brainwave power values of the elderly in an assisted living facility.

\begin{tabular}{|c|c|c|c|c|}
\hline & \multicolumn{2}{|c|}{ Warm Cloth } & \multicolumn{2}{|c|}{ Warm Water } \\
\hline & Power Value & Wilcoxon Test & Power Value & Wilcoxon Test \\
\hline \multicolumn{5}{|l|}{$\mathbf{F} \mathbf{p}_{1}$} \\
\hline Resting (baseline) & $12.6 \pm 2.8$ & - & $10.6 \pm 2.0$ & - \\
\hline Heat Stimulation & $16.1 \pm 2.9$ & 0.285 & $13.4 \pm 1.6$ & 0.028 \\
\hline Tactile Sensory Stimulation & $17.9 \pm 4.3$ & 0.799 & $14.5 \pm 2.0$ & 0.169 \\
\hline Resting & $11.9 \pm 2.3$ & 0.575 & $9.8 \pm 2.5$ & 0.959 \\
\hline \multicolumn{5}{|l|}{$\mathbf{F} \mathbf{p}_{2}$} \\
\hline Resting (baseline) & $12.2 \pm 3.5$ & - & $10.5 \pm 2.3$ & - \\
\hline Heat Stimulation & $17.5 \pm 3.2$ & 0.059 & $14.8 \pm 2.4$ & 0.007 \\
\hline Tactile Sensory Stimulation & $20.0 \pm 4.1$ & 0.202 & $14.3 \pm 1.4$ & 0.098 \\
\hline Resting & $13.6 \pm 2.8$ & 0.575 & $10.4 \pm 2.9$ & 0.799 \\
\hline \multicolumn{5}{|l|}{$\mathrm{C}_{3}$} \\
\hline Resting (baseline) & $23.2 \pm 7.5$ & - & $15.4 \pm 3.8$ & - \\
\hline Heat Stimulation & $26.1 \pm 5.8$ & 0.575 & $20.4 \pm 4.1$ & 0.017 \\
\hline Tactile Sensory Stimulation & $20.4 \pm 3.4$ & 0.721 & $16.9 \pm 2.4$ & 0.575 \\
\hline Resting & $19.5 \pm 4.1$ & 0.878 & $19.4 \pm 7.1$ & 0.575 \\
\hline \multicolumn{5}{|l|}{$\mathrm{C}_{4}$} \\
\hline Resting (baseline) & $26.2 \pm 8.2$ & - & $17.1 \pm 4.0$ & - \\
\hline Heat Stimulation & $28.8 \pm 5.8$ & 0.445 & $25.5 \pm 4.7$ & 0.013 \\
\hline Tactile Sensory Stimulation & $24.2 \pm 3.7$ & 0.799 & $22.6 \pm 4.1$ & 0.047 \\
\hline Resting & $22.1 \pm 5.2$ & 0.386 & $22.8 \pm 7.6$ & 0.241 \\
\hline
\end{tabular}

Table 6. $\beta$-Band brainwave power value of the elderly in an assisted living facility.

\begin{tabular}{|c|c|c|c|c|}
\hline & \multicolumn{2}{|c|}{ Warm Cloth } & \multicolumn{2}{|c|}{ Warm Water } \\
\hline & Power Value & Wilcoxon Test & Power Value & Wilcoxon Test \\
\hline \multicolumn{5}{|l|}{$\mathbf{F} \mathbf{p}_{1}$} \\
\hline Resting (baseline) & $15.7 \pm 3.7$ & - & $13.9 \pm 3.0$ & - \\
\hline Heat Stimulation & $21.5 \pm 6.5$ & 0.093 & $19.8 \pm 4.0$ & 0.005 \\
\hline Tactile Sensory Stimulation & $30.5 \pm 8.0$ & 0.022 & $20.4 \pm 3.2$ & 0.009 \\
\hline Resting & $16.4 \pm 4.3$ & 0.799 & $11.8 \pm 2.8$ & 0.374 \\
\hline \multicolumn{5}{|l|}{$\mathbf{F} \mathbf{p}_{2}$} \\
\hline Resting (baseline) & $17.2 \pm 5.2$ & - & $14.7 \pm 3.4$ & - \\
\hline Heat Stimulation & $27.0 \pm 9.7$ & 0.114 & $24.5 \pm 4.8$ & 0.005 \\
\hline Tactile Sensory Stimulation & $30.6 \pm 6.5$ & 0.028 & $25.5 \pm 5.6$ & 0.011 \\
\hline Resting & $14.8 \pm 3.1$ & 0.878 & $13.2 \pm 3.4$ & 0.241 \\
\hline \multicolumn{5}{|l|}{$\mathrm{C}_{3}$} \\
\hline Resting (baseline) & $17.3 \pm 3.5$ & - & $14.8 \pm 3.4$ & - \\
\hline Heat Stimulation & $26.8 \pm 6.3$ & 0.005 & $24.5 \pm 5.3$ & 0.005 \\
\hline Tactile Sensory Stimulation & $27.7 \pm 5.8$ & 0.114 & $25.5 \pm 3.7$ & 0.009 \\
\hline Resting & $18.1 \pm 3.7$ & 0.646 & $16.7 \pm 4.3$ & 0.169 \\
\hline \multicolumn{5}{|l|}{$\mathrm{C}_{4}$} \\
\hline Resting (baseline) & $20.3 \pm 4.0$ & - & $18.4 \pm 4.8$ & - \\
\hline Heat Stimulation & $42.9 \pm 17.3$ & 0.007 & $36.2 \pm 9.9$ & 0.005 \\
\hline Tactile Sensory Stimulation & $41.8 \pm 11.5$ & 0.013 & $37.9 \pm 9.4$ & 0.009 \\
\hline Resting & $21.7 \pm 5.4$ & 0.959 & $17.6 \pm 5.2$ & 0.721 \\
\hline
\end{tabular}

Note: $\mathrm{n}=10$. $\mathrm{Fp}_{1}$ : left frontal lobe region, $\mathrm{C}_{3}$ : left centroparietal region.

$\mathrm{Fp}_{2}$ : right frontal lobe region, $\mathrm{C}_{4}$ : right centroparietal region.

Power Value is an average value $\pm \operatorname{SE}\left(\mu \mathrm{V}^{2}\right)$.

$\mathrm{p}$-value is used to show the results of multiple comparisons.

$\mathrm{p}<0.016$ is set as the level of significance (with Bonferroni correction). 


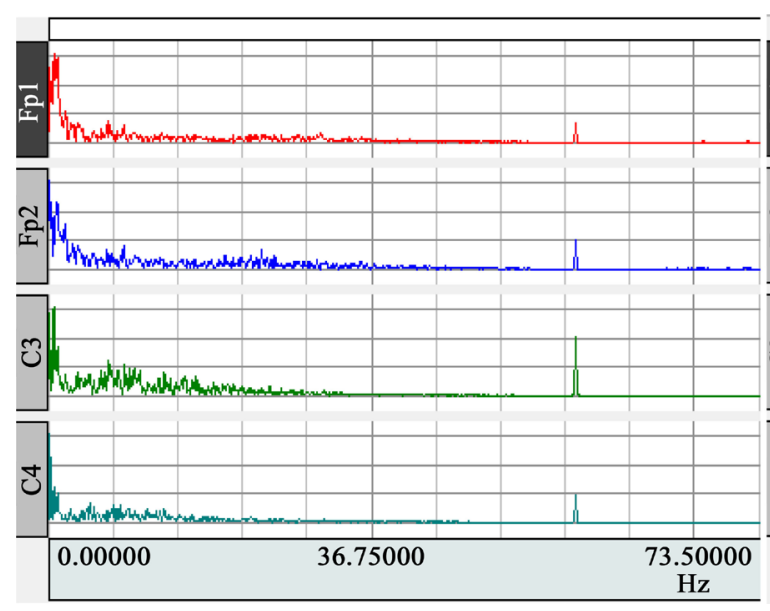

Note: Data at the time of heat stimulation.

(a)

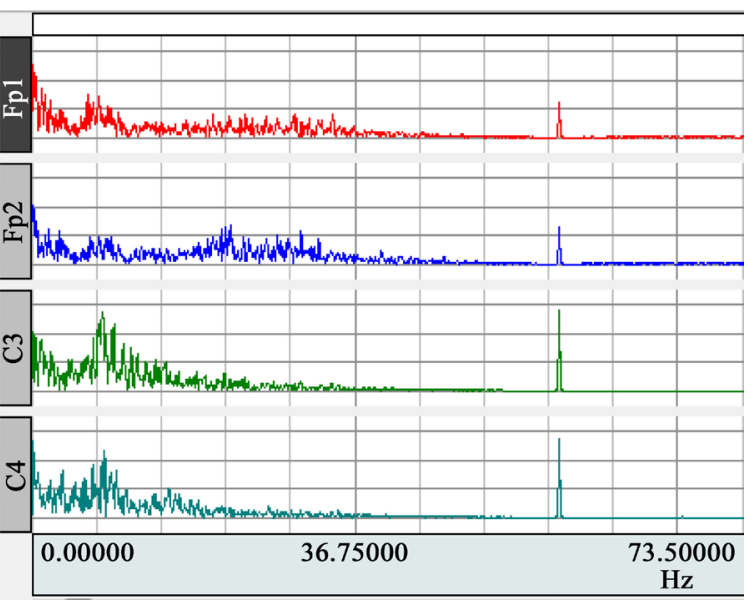

(b)

Figure 3. Electroencephalographic data of the elderly in an assisted living facility. (a) Heat stimulation (warm cloth); (b) Heat stimulation (warm water).

stimulation through drying the hands with a dry towel; however, this is likely because they regularly receive stimulation on their fingers and hands, and it is not perceived as noticeable stimulation. On the other hand, the elderly living in the facility are less likely to receive stimulation on their fingers and hands, and thus the brain picks up the experience as something stimulating.

In this research, the setting is such that the stimulation is provided through soaking the hand in warm water and then patting dry with a dry towel. However, in real life handwashing, people will likely use soap or rub their hands together and will experience a greater stimulation, and thus will have a more significant effect on cerebral activation. From the perspective of stimulating the senses of the elderly, once again using warm water over warm cloths can be seen as being more preferable.

This study shows the effectiveness of using warm water as a way to stimulate the brain in the elderly in a sitting position, and it is thought to be applicable in providing care before meals. There are reports of a correlation between the elderly choking on food and those who have Alzheimer's disease or Parkinson's [3] [17]. In Japan, mochi (sticky rice cakes), mini-cup gelatins, and other candies are categorized as dangerous choking hazards [18]. It is important to keep these facts about food and diseases in mind when providing handwashing care to raise the alertness before meals.

For future studies, widening the range of the subjects to include individuals with severe cases of dementia and checking for the alertness level before and after handwashing with warm water, as well as studying the condition of swallowing itself will be necessary.

\section{Acknowledgements}

I would like to thank the residents and staff of the elderly care facility Haginosato hat cooperated with this study.

This work was supported by JSPS KAKENHI Grant Number 21890282.

\section{References}

[1] Ministry of Health, Labour and Welfare: 2013 Demographic Survey, Vital Statistics, Vol. 1, Table 5-32, Mortality Rate in Percentage by Age Based on Type of Accident. http://www.e-stat.go.jp/SG1/estat/List.do?lid=000001108740

[2] World Health Organization. International Statistical Classification of Diseases and Related Health Problems, Tenth Revision: Volume II, Instruction Manual 2010 Edition. World Health Organization, Geneva. http://www.who.int/classifications/icd/en/

[3] Kramarow, E., Warner, M. and Chen, L.-H. (2014) Food-Related Choking Deaths among the Elderly. Injury Prevention, 20, 200-203. http://dx.doi.org/10.1136/injuryprev-2013-040795

[4] Tokushige, A., Aso, Y., Ibe, A., Oka, M. and Katayama, M. (2009) An Electroencephalographic Study of Brain Activ- 
ity Produced by Postural Change from Supine to Sitting Position. Transactions of the Japanese Society for Medical and Biological Engineering, 47, 15-27.

[5] Tokushige, T. (2009) Nursing Care and Assisting the Patients to Be in a Sitting Posture from the Perspective of Cerebral Activation by Looking at the $\alpha$ and $\beta$-Band Power Value in the Brainwaves. PhD Dissertation, Osaka University, Osaka.

[6] Kawamura, S., et al. (2004) Basic Nursing_Basic Nursing Skills. Nursing Graphica, 18, 222-242.

[7] Taneike, R. (2005) Perfect Nursing Skill Manual. Shorin-Sha, Tokyo, 158-161.

[8] Tsuboi, R., et al. (2006) Thoughtful Basic Nursing Skills II. Nouvelle Hirokawa, Tokyo, 96-113.

[9] Fukai, K. (2007) Basic Nursing II. Shintaikei Kangogaku Zensho, 12, 28-46.

[10] Takeno, T., Kitakata, H., Semura, C., et al. (2000) The Effect of Using Aroma Therapy in Hand Bathing in Relaxation. Nihon Kango-Gakkai Ronbunshu, Kango Sogo, 31, 18-20.

[11] Kurita, I., Sano, H., Tachibana, M., et al. (2004) Consideration on the Effect of Hand Bathing, Focusing on POMS and CVR-R. Nihon Kango-Gakkai Ronbunshu, Kango Sogo, 35, 148-150.

[12] Morita, K., Toyoda, M. and Seino, K. (2002) The Influence Hand Bathing Has on Skin Temperature, from the Results of Durmal-Thermometer and Thermography. Nihon Kango-Gakkai Ronbunshu, Kango Sogo, 33, 251-253.

[13] Okada, J. and Fukai, K. (2003) The Influence Hand Bathing Has in the Temperature of the Skin as Well as the Sense of Temperature and Pleasantness. Kawasaki Iryo Fukushi Gakkai-Shi, 13, 317-323.

[14] Masuda, C. (2003) The Effect of Stimulating the Five Senses of Children with Poor Reaction Due to Acute Encephalopathy. Clinical Study, 24, 124-129.

[15] Iwane, N., Mizuta, M., Suishu, C., et al. (2011) Consideration on the Effect Hand Bathing Has on the Elderly’s Sleep Habits. Wakayama Prefectural Medical University Health and Nursing Department Summary, 8, 29-33.

[16] Sano, S., Watanabe, K., Mikami, H., et al. (2010) The Effect Hand Bathing Has on Sleeping. Nihon Kango-Gakkai Ronbunshu, Kango Sogo, 41, 135-138.

[17] Wu, W.-S., Sung, K.-C., Cheng, T.-J. and Lu, T.-H. (2015) Associations between Chronic Diseases and Choking Deaths among Older Adults in the USA: A Cross-Sectional Study Using Multiple Cause Mortality Data from 2009 to 2013. BMJ Open, 5, e009464. http://dx.doi.org/10.1136/bmjopen-2015-009464

[18] Food Safety Commission of Japan: Risk Assessment Report Choking Accidents Caused by Food. https://www.fsc.go.jp/english/ 